\title{
Um estudo da mulher no processo educativo medieval do século IX: reflexões sobre o manual de Dhuoda
}

\section{A study of women in the medieval educational process of the ninth century: reflections on the Dhuoda's manual}

\section{Un estudio de la mujer en el proceso educativo medieval del siglo IX: reflexiones sobre el manual de Dhuoda}

\author{
Terezinha Oliveira ${ }^{a} \mathbb{D}^{\mathbb{D}}$; Ana Paula dos Santos Viana ${ }^{\mathrm{b}}$ (D) \\ ${ }^{a}$ PhD em História e Filosofia da Educação pela USP. Doutora em História pela Universidade Estadual Paulista Júlio de Mesquita \\ Filho. Professora Titular da Universidade Estadual de Maringá (UEM), Maringá, PR, Brasil - E-mail: teleoliv@gmail.com \\ ${ }^{\text {b }}$ Pedagoga, Mestre em Educação, Doutoranda em Educação: História e Historiografia da Educação pela Universidade Estadual de \\ Maringá (UEM), Maringá, PR, Brasil - E-mail: ana psviana@hotmail.com
}

Resumo: O objetivo desse artigo é refletir sobre o lugar da mulher no processo educativo medieval do século IX. Este estudo pauta-se no âmbito da história da educação e será feito segundo reflexões do Manual La educación cristiana de mi hijo, de Dhuoda (c. 800-843). A autora foi uma mãe pertencente à nobreza, de origem germânica, que viveu no período da dinastia carolíngia. A proposta é evidenciar, com o escrito dessa mulher 'educadora' o lugar do feminino na educação medieval do século IX. Ao prezar pela formação humana e intelectual de seu filho, Dhuoda redige o Manual fundamentando-se nos escritos clássicos de sua época. Nesse sentido, a proposta é evidenciar que neste período havia uma preocupação com a educação da criança e, no caso da nobreza, essa ‘função’ era feminina.

Palavras-chave: Dhuoda. Manual. Mulher. Processo educativo medieval.

\begin{abstract}
The aim of this paper is to reflect on the place of women in the medieval educational process of the ninth century. This study is based on the history of education and will be done according to reflections of the Manual Christian education of my son, by Dhuoda (c. 800-843). The author was a mother belonging to the nobility, of Germanic origin, who lived in the period of the Carolingian dynasty. The proposal is to show, with the writing of this woman 'educator', the place of the feminine in medieval education of the ninth century. In cherishing the human and intellectual formation of his son, Dhuoda writes the Manual based on the classic writings of his time. In this sense, the proposal is to show that in this period there was a concern with the education of the child and, in the case of the nobility, this 'function' was female.
\end{abstract}

Keywords: Dhuoda. Manual. Woman. Medieval Educative Process.

Resumen: El propósito de este artículo es reflexionar sobre el lugar de las mujeres en el proceso educativo medieval del siglo IX. Este estudio se basa en la historia de la educación y se realizará de acuerdo con las reflexiones del Manual $L a$ educación cristiana de mi hijo, por Dhuoda (c. 800-843). La autora era una madre perteneciente a la nobleza, de origen germánico, que vivió en el período de la dinastía carolingia. La propuesta es mostrar, con la escritura de esta 'educadora', el lugar de lo femenino en la educación medieval del siglo IX. Al apreciar la formación humana e intelectual de su hijo, 
Dhuoda escribe el Manual basado en los escritos clásicos de su tiempo. En este sentido, la propuesta es mostrar que en este período hubo una preocupación con la educación del niño y, en el caso de la nobleza, esta "función" era femenina.

Palabras clave: Dhuoda. Manual. Mujer. Proceso educativo medieval.

\section{Como citar o artigo:}

OLIVEIRA, Terezinha. VIANA, Ana Paula dos Santos. Um estudo da mulher no processo educativo medieval do século IX: reflexões sobre o Manual de Dhuoda. Revista de Ciências Humanas, v.52, 2018. DOI: 10.5007/21784582.2018 .55140

\section{UMA PROPOSTA DE EDUCAÇÃO MEDIEVAL DE AUTORIA FEMININA}

Estudar a educação de épocas anteriores ao tempo presente, em especial, as questões e preocupações presentes no escrito de Dhuoda se justifica, a nosso ver, por permitir conhecer e refletir acerca da mulher e da sociedade em suas características fundamentais no curso da história.

Cumpre observar que a História e a História da Educação pautam este estudo, em que tomamos como referência os pressupostos teórico-metodológicos da História Social sob a perspectiva da longa duração preconizada por Braudel ${ }^{1}$.

Estudar e refletir sobre 'ser mulher' nos mais variados tempos históricos designa um movimento histórico que há décadas vem despertando o interesse de pesquisadores. Esta disposição, certamente, pode ser entendida e contextualizada dentro da própria história dos movimentos feministas que, dentre outros aspectos, assinalaram a necessidade de a mulher ser vista como sujeito histórico e, por conseguinte, como possível objeto de estudo.

Longe de esgotar a discussão acerca destes movimentos e seus desdobramentos, a 'história das mulheres' faz parte desse processo buscado com afinco pelos movimentos feministas no século XIX e XX (PERROT, 1995; ROIZ, 2008; PINTO, 2010). Percebemos, com esses autores, que a mulher não somente tem história, como faz e fez história, haja vista, por exemplo, a conquista do direito ao voto, a inserção no mercado de trabalho (carreira profissional), direitos buscados por aqueles movimentos e que culminaram, nesse campo de pesquisa. Desse modo, observamos que a 'história das mulheres' é, na atualidade, um campo de pesquisa consolidado universalmente nas universidades, ainda que em cada país haja particularidades e níveis diferenciados de aceitação e desenvolvimento deste campo. Os movimentos feministas, em linhas gerais, partem do pressuposto

\footnotetext{
${ }^{1}$ Essa perspectiva de longa duração nos permite, estando no presente, estudar e refletir sobre temas oriundos do passado, mas que, guardadas as devidas proporções, nos inquietam e são pertinentes de ser analisado por possibilitar pensar nas rupturas e permanências com questões atuais, como o papel da mulher, haja vista que "[...] essa duração social, esses tempos múltiplos e contraditórios da vida dos homens, que não são apenas a substância do passado, mas também o estofo da vida social atual. Uma razão a mais para assinalar com vigor, no debate que se instaura entre todas as ciências do homem, a importância, a utilidade da história, ou, antes, da dialética da duração, tal como ela se desprende do mister, da observação repetida do historiador; pois nada é mais importante, a nosso ver, no centro da realidade social, do que essa oposição viva, íntima, repetida indefinidamente entre o instante e o tempo lento a escoar-se" (BRAUDEL, 2011, p. 43).
} 
da necessidade de isolar a mulher do contexto da história da humanidade, por considerar que, em consonância a uma mesma época, sua compreensão e experiência histórica podem ser muito distintas da compreensão e experiência do homem. Assim, dentro dessa perspectiva, autoras como Escandón (1991), Kelly (1976), questionam a pertinência de se direcionar a periodização histórica tradicional à História das Mulheres, por considerar que os contextos históricos considerados 'progressistas' no decorrer do processo civilizatório ocidental (civilização ateniense, Renascimento, Revolução Francesa, etc.) reputaram uma perda considerável na ação, atuação e decisão das mulheres.

Desse modo, como decorrência de um novo olhar para as mulheres no curso da história, foram propostas novas construções teóricas acerca dessa temática/problemática e, com elas, novos métodos analíticos, dentre eles, destaca-se o dos estudos de gênero. Nesta nova concepção, os gêneros feminino e masculino são compreendidos como construções culturais associadas às relações hierárquicas de poder desfavoráveis ao gênero feminino. Contudo, as categorias analíticas não se resumem a apenas esta concepção, há outras tendências analíticas, conforme podem ser observadas e estudadas em Scott (1989). A primeira perspectiva limita-se a mera descrição das relações entre os sexos. A segunda confere à teoria dos gêneros a possibilidade de explicar a organização econômica, política e social das relações entre os sexos. A terceira vincula-se ao materialismo histórico, propondo-se não desviar da crítica feminista. Por fim, encontram-se aquelas que se fundamentam na psicanálise para elucidar a reprodução da identidade genérica do sujeito (SCOTT, 1989).

Ao apresentarmos essas perspectivas, ressaltamos que nosso objetivo não se direciona a comparações culturais e de redefinição do papel da mulher no processo histórico, tão pouco compreendemos a mulher como um ser isolado das relações e convívio social, concebendo o homem como um ser subversivo, mas sim, pensamos ser pertinente e fomentador um estudo do papel da mulher no curso da História.

Entendemos que a pesquisa permite diversas possibilidades de análises, mas sem moldar a realidade histórica às preocupações atuais de recuperação do prestígio feminino e de redefinição do papel da mulher, ou seja, evitaremos discursos destinados à caracterização dos comportamentos sociais com relação à mulher como positivos ou negativos, buscando não incorrer em juízos de valor.

[...] se o julgamento apenas acompanhava a explicação, o leitor estará livre para pular a página. Por infelicidade, à força de julgar, acaba-se, quase fatalmente, por perder até o gosto de explicar. Com as paixões do passado misturando seus reflexos aos partis pris do presente, o olhar se turva sem remédio e, assim como o mundo dos maniqueus, a humana realidade vira apenas um quadro em preto e branco. Montaigne já nos chamara a atenção: “A partir do momento em que o julgamento pende para um lado, não se pode evitar de contornar e distorcer a narração nesse viés." Do mesmo modo, para penetrar uma consciência estranha separada de nós pelo intervalo das gerações, é preciso quase se despojar de seu próprio eu. (BLOCH, 2001, p. 126). 
Essa compreensão revela nosso entendimento de História e dos pressupostos teóricos desta pesquisa que se insere no âmbito da História da Educação. Assim, os ensinamentos de Bloch (2001), Febvre (1989), orientam que o que deve nortear os estudos, especialmente no campo da história, é a compreensão do processo histórico, e, portanto, não nos cabe julgar sob a finalidade de apresentar o certo e o errado. Compreendemos, desse modo, que se estivermos 'abertos ao conhecimento' procuraremos, primeiro, ler determinados escritos/autores para então, chegarmos a compreensão e, possíveis, reflexões.

Pastor (1986) adverte que ao separar a história da mulher da história do homem podemos incorrer no risco de impossibilitar a compreensão mais complexa, que é a sociedade. Nesse sentido, estudar o Manual de Dhuoda é um exercício de reflexão sobre a mulher, suas particularidades e relações estabelecidas entre seus pares e a sociedade em que esteve inserida. Compreende-se, dessa forma, que o pesquisador quer entender o que se passa com as pessoas de seu tempo e, por isso, busca conhecer outras experiências, diferentes das suas próprias, pois " [...] A incompreensão do presente nasce fatalmente da ignorância do passado. Mas talvez não seja menos vão esgotar-se em compreender o passado se nada se sabe do presente" (BLOCH, 2001, p. 65). Nesse sentido, por justamente se preocupar com os problemas do presente que o historiador busca compreender o passado.

Estudar a obra em tela é pertinente ao âmbito da História da Educação e, por conseguinte, aos estudos femininos, pois possibilita fomentar o debate acerca da formação dos sujeitos singulares (seja da mulher que redigiu o Manual, seja do filho que recebera por meio desse escrito a educação pretendida por essa figura feminina, sua 'educadora'), propondo-nos conhecer autores que não são estudados com tanta frequência, mas que trataram da educação, do processo de ensino e aprendizagem e a ação e atuação da mulher em determinado tempo histórico.

Analisar o Manual ${ }^{2}$ de Dhuoda (c. 800-843), intitulado, La educación cristiana de mi hijo ${ }^{3}$ é, a nosso ver, pensá-lo como um projeto educacional, um instrumento resultante daquela que ensina

\footnotetext{
${ }^{2}$ Destacamos que ao remetermos a obra de Dhuoda a denominamos de Manual, pois é a forma como ela é mais conhecida. "No original e valioso Manual para meu filho, escrito por Dhuoda, uma senhora alemã, a fim de instruir o seu filho mais velho sobre as verdades religiosas, e de lhe inculcar o dever da fidelidade para com o Rei e Senhor, depara-se um precioso documento, muito esclarecedor sobre os vários aspectos da crença e da vida na conturbada época do final do reinado de Luís, o Piedoso, quando os aristocratas carolíngios começaram a revoltar-se contra o Imperador, e quando se iniciou a precoce e inesperada desagregação do império formado por Carlos Magno" (NUNES, 1995, P. 135).

${ }^{3}$ Formalmente, o Manual está dividido em 81 capítulos, separados por sua vez em onze partes, conforme o conteúdo. Essas partes são precedidas por abreviaturas, introdução (contendo oito subitens), bibliografia, epigrama, prólogo, prefácio e finalizadas com os índices (bíblicos, de autores e obras antigos, de autores modernos e o índice geral). Quanto ao conteúdo, podemos dividi-lo em três partes principais: a primeira expressa as relações do cristão para com Deus; a segunda diz respeito ao relacionamentos com o próximo e a terceira mostra o caminho da perfeição pessoal mediante a perfeita ordenação dos dias. Lauand (1986) apresenta um resumo desse conteúdo com o objetivo de situar o leitor no conjunto da obra, apontando o que a autora aborda em cada uma das onze partes: "I - Dhuoda fala inicialmente de Deus. Do amor de Deus, da busca de Deus, da grandeza e sublimidade de Deus. II - A seguir, o mistério da Trindade, as virtudes teologais, com especial ênfase na caridade. Há conselhos práticos sobre o modo de orar. III - A moral social. Os deveres
} 
para aquele que, potencialmente, aprenderá. Significa, também, a possibilidade de refletir acerca da importância feminina no processo educativo da Idade Média. É, pois, sob esta dupla perspectiva que objetivamos tratar esse estudo: de um lado, analisaremos um manual pedagógico para a formação de uma criança nobre do século IX, cujo formato literário é o Espelho de príncipe ${ }^{4}$, e, com isso, por outro lado, expressaremos e refletiremos sobre o papel educacional desempenhado por uma mãe no medievo.

Procuraremos, assim, evidenciar que Dhuoda, uma mulher do século IX apresenta, com a escrita de seu Manual e os ensinamentos nele contido e prezados à formação de seu filho, Guilherme, uma proposta de educação medieval. A autora vive e escreve no contexto das mudanças políticas e sociais do século IX, das quais se destacam o início das bases da sociedade feudal, a desintegração do Império Carolíngio e o papel da Igreja como reguladora dessa sociedade (GUIZOT, 1907). Ao ser partícipe desse contexto, Dhuoda demonstra compreender a pertinência de questões, preceitos e princípios essenciais à vida em sociedade, no seu caso, vivendo na corte de Carlos, o Calvo e, em específico, à existência e formação de seu filho. Dentre as questões e preceitos, encontramos o papel da fidelidade nas relações feudo-vassálicas, das quais seu filho, na condição de príncipe, faria parte ao servir nessa corte.

Estamos, assim, nos referindo à importância histórica e educacional da fidelidade que se remonta ao conturbado contexto de desintegração do Império Carolíngio, em que os príncipes nômades e seus companheiros aliavam-se e criavam laços temporários no intuito de combater e saquear. Esses laços embasavam as relações que se desenvolveram entre os senhores e seus vassalos no período feudal. Conforme Montesquieu (1982), inicialmente não havia feudos e sim vassalos.

Não havia feudos, porque os príncipes não tinham terras para dar; ou, antes, os feudos eram os cavalos de batalha, as armas, as refeições. Havia vassalos porque havia homens fiéis que estavam empenhados por sua palavra, que estavam engajados para a guerra, e que prestavam

de Guilherme para com seu pai e superiores. IV - Os vícios e as virtudes (tal como nos espelhos carolíngios). V - As tribulações que ameaçam o homem e de como não devem impedi-lo de da glória a Deus. VI - O caminho para Guilherme atingir a perfeição. VII - O duplo nascimento (carnal de espiritual) e a dupla morte (temporal e eterna). VIII - De como Guilherme deve orar pelo clero, pelos reis, pelos familiares vivos e defuntos etc. IX - Antes de terminar o livro, Dhuoda desenvolve uma curiosa aritmética onde mostra um sentido bíblico para cada número. X - Faz o histórico da vida de Guilherme, fala dos defuntos da família, resume o Manual e expressa o epitáfio que ela quer sobre sua própria tumba. XI - O manual termina com uma indicação sobre o modo como Guilherme deve cantar os salmos. (LAUAND, 1986, p. 124125).

${ }^{4}$ Gênero literário que, no período medieval, era composto por reflexões de orientação moral e política. Estas reflexões estavam, em sua maioria, direcionadas ao modelo cristão de virtudes. A finalidade desse formato literário era o de apresentar uma proposta de formação e educação moral, política e religiosa para formar os jovens desse período. Conforme observa Nunes (1995, p. 139): "No tempo de Dhuoda, e já em épocas anteriores, os clérigos soíam escrever livros de aconselhamento político para os príncipes e para jovens nobres. Essas obras pertenciam ao gênero literário dos 'espelhos'. Na época carolíngia os termos manual e espelho eram empregados como sinônimos. Aliás, como observa Riché, esse gênero literário remonta à antiguidade egípcia e hebraica, passou às civilizações bizantina e árabe. Os 'espelhos' apresentavam-se como guias de orientação política, de educação física, moral e literária para jovens aristocratas". 
mais ou menos o mesmo serviço que fizeram depois para os feudos (MONTESQUIEU, 1982, p. 621).

A terra começou a ser dada e recebida como feudo somente quando esses homens começaram a se fixar em território. Tal transformação começou a ocorrer no século VIII, intensificando-se com a ação dos sucessores de Carlos Magno (ca. 742-814), principalmente a dos filhos de Luís, o Piedoso (778-840): Lotário (795-855), Pepino (797-838), Luís, o Germânico (804-876) e Carlos, o Calvo (823-877). Em decorrência dos conflitos travados entre esses irmãos, cada um deles passou a distribuir terras aos seus correligionários com o intuito de proteger suas vidas e propriedades. Aos poucos, a unidade política e territorial, que Carlos Magno (ca. 742-814) buscara conquistar para seu reino, foi se fragmentando, dando início às relações feudais. O processo propiciou o fortalecimento da aristocracia territorial: uma vez beneficiados pelo rei, alguns homens tornaram-se donos de grandes parcelas de terra (DIAS, 2001).

Nesse sentido, o fato de os homens passarem a estreitar laços temporários para combater ou saquear propiciou o desenvolvimento das relações entre os senhores e vassalos, relações essas características do período feudal.

A igreja também teve papel importante nesse contexto: “[...] Ao cair o império e derrubadas suas instituições civis, apenas permaneceu a Igreja como organização" (ZILLES, 1996, p. 14). Observamos que a Igreja foi a instituição que conseguiu, de certa maneira, resistir à 'maré' nômade e tornar-se organizada e relativamente articulada, oferecendo aos homens um mínimo de condições para a manutenção da vida e para a reordenação da sociedade (OLIVEIRA, 1997).

De acordo com Falbel (1995), o processo de feudalização da Igreja e da sociedade carolíngia como um todo foi acelerado pelo desmembramento interno e pela grande repartição de terras, o que fortaleceu as ambições da aristocracia. Assim, não foi fácil conduzir uma política que harmonizasse a divisão do Império ocorrida entre os descendentes de Luís, o Piedoso.

Guizot aponta dois elementos que tiveram papéis peculiares nesse processo: tanto a Igreja quanto os príncipes contribuíram para a construção e para a subordinação da nova forma da sociedade - a feudal.

[...] Guizot pôde captar o princípio vital que fizera da Igreja a principal das instituições da Idade Média e aquela que possibilitou aos homens organizarem-se socialmente, explicando, assim, por que a religião tornou-se ideologia dominante nessa época histórica. Acompanhar, pois, as transformações por que passou a sociedade religiosa, é acompanhar o processo de transformação da própria sociedade (OLIVEIRA; MENDES, 1999, p. 5).

Podemos, assim, compreender que a Igreja se tornou fonte reguladora, pois influenciou a vida moral dos homens e, servindo de modelo, interferiu em seu comportamento e em sua maneira de viver. 
É justamente nesse contexto social que Dhuoda viveu e foi influenciada em sua formação. Ela era esposa de Bernardo (795-844), duque de Septimania, que desempenhara altas funções como servidor do imperador Luís, o Piedoso (778-840), apoiando-o na luta contra Lotário (795-855). "No conflito entre os filhos de Luís, o Piedoso, Bernardo apoiou Pepino II de Aquitânia, mas após a batalha de Fontenay em Puisaye (22/6/841) [...]" por ter fracassado em seu empenho nessa batalha, passou a apoiar e a dever fidelidade a Carlos, o Calvo, que se tornou seu rei e senhor e, como penhor do amparo recebido, colocou Guilherme, seu primogênito, a serviço desse senhor (NUNES, 1995, p. 139).

A concepção de fidelidade ocupa um lugar de destaque no Manual de Dhuoda, pois se observa que a sobrevivência de Guilherme dependeria da maneira como ele conduziria sua vida ao servir na corte; haja vista que, provavelmente, Carlos, o Calvo, manteria vivos somente os nobres que lhe consagrassem essa virtude: a fidelidade.

[...] debes servir a tu señor y serle fiel en cualquier circunstancia. Cuando lo hayas descubierto, observa con detalle sus órdenes para cumprilas con fidelidad. Ten en cuenta también y estudia a quienes lo sirven con celo y fidelidad, y aprende de ellos las normas de comportamiento; haciendo tuyo ejemplo, con el favor y la protección divina [...] (DHUODA, 1995, p. 87-88).

Para Dhuoda, toda honra e autoridade é um dom divino, por isso Guilherme deve respeito a Deus, ao pai e deve também servir aos seus senhores fielmente, pois desse comportamento depende sua vida. Nas ações do filho está a possibilidade de preservação da linhagem e dos bens da família. Com isso, ela manifesta uma dupla percepção: a do embate político que assolava a dinastia e o Império Carolíngio e, em correlação com esta, a de que a prática da fidelidade se apresentava como forma de sobrevivência.

Nesse sentido, compreendemos a pertinência de Guilherme conhecer e agir fielmente. Isso nos leva a entender a preocupação da autora em expressar no Manual os conhecimentos necessários à formação e existência de seu filho. A concepção da fidelidade, portanto, é apresentada no Manual em dupla acepção, a saber, ela faz parte das relações feudo-vassálicas as quais Guilherme vivenciou e, por isso, era preciso que ele as cultivasse enquanto virtude, pois não nasceu de posse da compreensão de seu significado. Tal fato nos remete à concepção aristotélica da ideia de virtude moral, de hábito.

Sendo a virtude [...] de dois tipos, nomeadamente, intelectual e moral, a intelectual é majoritariamente tanto produzida quanto ampliada pela instrução, exigindo, conseqüentemente, experiência e tempo, ao passo que a virtude moral ou ética é o produto

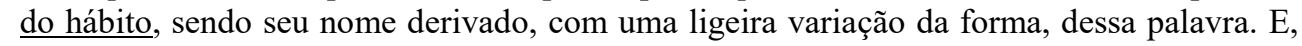
portanto, fica evidente que nenhuma das virtudes morais é em nós engendrada pela natureza, uma vez que nenhuma propriedade natural é passível de ser alterada pelo hábito. Por exemplo, é da natureza da pedra mover-se para baixo, sendo impossível treiná-la para que se mova para cima, [...]. As virtudes, portanto, não são geradas em nós nem através da natureza 
nem contra a natureza. A natureza nos confere a capacidade de recebê-las, e essa capacidade é aprimorada e amadurecida pelo hábito (ARISTÓTELES, 1985, p. 67, grifo nosso).

Tornando a fidelidade uma virtude, ou seja, um hábito em suas ações cotidianas, Guilherme, potencialmente, cumpriria com seu dever na corte e, ao mesmo tempo, estaria se apropriando do processo de formação almejado por sua 'educadora'.

Observa-se assim que, por questões políticas, Guilherme foi afastado do convívio familiar para, junto de seu pai, servir a corte. E para tanto, era preciso conhecer, ter uma formação. Por isso, compreendemos que o Manual, além de expressar o conhecimento de Dhuoda, resulta na forma encontrada pela autora para fazer-se presente na educação do filho e, também, nas funções que essa mulher medieval desenvolveu. Com a ausência, quase constante, de seu esposo, Dhuoda desempenha algumas atividades, entre elas a administração das propriedades (o que inclui o pagamento e aquisição de dívidas), o recebimento de corveias, doações aos mosteiros e Igrejas, bem como a educação do filho.

\section{DHUODA: UMA MULHER CULTA E CRISTÃ}

Dhuoda é uma autora pouco divulgada e estudada no campo da História da Educação e no ambiente universitário. Apesar disso, sua obra transcende sua época e lugar de origem e torna-se, para o leitor, um documento histórico e original. Ainda que a biografia de Dhuoda seja pouco conhecida, Dib (2005) afirma que Dhuoda descendia de família nobre. Ela era filha de Sancho I Lopes, duque de Gacuña (775-816) e de Aznárez de Aragon (?). De acordo com Merino (1995), eles provinham da região da Austrasia, no norte da Gália.

Dhuoda e Bernardo casaram-se em 29 de junho de 824 na capela do palácio de Aquisgran. Pouco depois de seu enlace matrimonial, Bernardo foi nomeado marquês da Marca da Espanha e, apartando-se de sua esposa, dirigiu-se para uma corte longínqua de Aquisgran. Nomeado camerarius do Imperador por três anos, o conde Bernardo permaneceu na corte, distante de sua família até a morte de Luís, o Piedoso (MERINO, 1995).

O fato de seu casamento ter ocorrido na capela do palácio imperial de Aquisgran revela a ascendência nobre da família de Dhuoda e de Bernardo. Sua elevada linhagem pode ser inferida também do excerto em que Dhuoda aconselha Guilherme a praticar a virtude da fidelidade para com Carlos, o Calvo:

Tienes a Carlos como señor, porque Dios, como creo, y tu padre Bernardo lo han elegido, para que tu le sirvas ya desde los primeros años de tu juventude con todas tus fuerzas; ten en cuenta que has salido de uma família elevada y noble por ambos padres [...] (DHUODA, 1995, p. 86, grifo nosso). 
Essa evidência de que a família de Guilherme pertencia à nobreza explica a preocupação de Dhuoda com a formação aristocrática do filho. A preservação dos costumes herdados era essencial para manter a linhagem nobre da família e, por isso, ela discorre acerca da nobreza e do grau de sua origem.

Dhuoda precisa mostrar desde as particularidades, como a história de sua família (suas origens), até aspectos mais amplos e complexos, inerentes à situação cultural e social de seu tempo, pois o processo educativo exposto em seu Manual tinha como finalidade auxiliar o filho a agir nesse conjunto.

É por compreender e, de certa forma, participar dos embates pertinentes ao seu contexto histórico que Dhuoda redige La educación cristiana de mi hijo. Na obra procura orientar e preparar o filho de 16 anos para o que ele teria de enfrentar. Afinal, Dhuoda vivenciou os fatos que marcaram a dinastia bem como a crise do Império carolíngio. A fragmentação do império em reinos, promovida pelos sucessores de Carlos Magno, e as novas invasões que os levaram à ruína no século IX não chegaram a destruir suas obras religiosas e culturais.

Além da cultura, a religiosidade também conseguiu florescer, e isto se deve à reforma de muitos monastérios, alguns dos quais remontavam à época do abade Bento de Aniane ${ }^{5}$ (750- 821), e à grande influência de mestres, como Alcuíno (c. 735-804), Jonas de Orleans (760-841), Walfido Estrabón (m.849) e João Escoto Erígena (815-877), mestre da escola palatina de Carlos, o Calvo (MERINO, 1995). O autor observa que autores como Alcuíno, Jonas de Orleans, Paulino de Aquileia, dentre outros, são os primeiros a compor Manuais (Espelhos) na Alta Idade Média.

Neste período, Manual era, de modo geral, sinônimo de Espelho conforme explicita Merino, servindo-se do sentido que a própria Dhuoda lhe atribui no prefácio: “[...] Encontrarás en él todo lo que deseas aprender; también hallarás un espejo en el que podrás contemplar sin duda la salud de tu alma [...] (DHUODA, 1995, p. 55). Afirma, contudo, que a obra escrita por Dhuoda tem um formato educacional elaborado em razão de seu cunho pedagógico e também da relação que ela faz dos textos bíblicos com as obras culturais clássicas, ou seja, da religião com a cultura/costumes da época.

\footnotetext{
Dhuoda era sin duda una de las mujeres más destacadas de su tiempo. Efectivamente, el Manual posee un enorme cúmulo de citas bíblicas, en mayor abundancia las Del Antiguo Testamento que las Del Nuevo, y da testimonio igualmente de los conocimientos más extendidos en la cultura de aquella época. Contiene, por ejemplo, un pasaje de La Historia de la Natureza de Plinio el Joven, lugares de la obra de Prudencio, de Donato, etc. Es verdad que los gramáticos de aquel entonces gustaban aducir um gran número de obras de los autores clásicos, y por lo que el Manual nos transmite, Dhuoda debió ser una de las alumnas más aplicadas en este sentido (MERINO, 1995, p. 28).
}

\footnotetext{
${ }^{5}$ Em Eco (2010, p. 219) encontramos informações sobre a Regra beneditina: “[...] durante o reinado de Luís, o Pio (c. 778-840, rei desde 814), esta regra é redefinida por Bento de Aniane (c. 750-821) e codificada, quer nas disposições sinodais estabelecidas em Aix-la-Chapelle em 816 e 818-819 quer nas prescrições dos capitularia monásticos com que é imposta a sua observância nos territórios do império".
} 
Dessa maneira, o autor nos permite refletir acerca da formação escolástica de Dhuoda. Ao destacar sua cultura e erudição, ele parece indicar a educação recebida pela autora pautada nas artes liberais (compostas pelas disciplinas do trivium e quadrivium). Observamos que essa possibilidade tem fundamento porque, segundo estudiosos como Pernoud (1984), as artes liberais constituíam a base do ensino medieval sendo, em particular, essenciais na formação das monjas e das mulheres nobres educadas nos mosteiros. Casadas ou assumindo uma vida enquanto religiosas, elas aprendiam a administrar o meio do qual passavam a fazer parte. Os mosteiros, por seu turno, desempenharam um importante papel na educação e na herança cultural da Idade Média. O trabalho dos monges copistas tornou possível que até hoje tenhamos acesso às obras literárias de Epicuro, Sêneca, Alcuíno, Cícero, dentre outros.

A cultura de Dhuoda encontra-se, assim, respaldada em diversos pensadores, como o gramático Donato (c. 320-380), Agostinho de Hipona (354-430), Bento de Nursia (480-547), Gregório Magno (540-604), Isidoro de Sevilha (560-636), e, sobretudo, na Sagrada Escritura. Podemos encontrar a influência das formulações destes autores ao longo do Manual.

Está escrito en la Arte del poeta Donato: $<<$ Te amo y soy amado por ti, te beso y soy besado por ti, te quiero y por ti soy querido; te conozco interiormente y soy conocido por ti $>>$. Y además: $<<$ Yo, de mí, para mí o por mí $>>$. Y en plural: $<<$ A ellos, de ellos y para ellos o por ellos $>>$ [...] (DHUODA, 1995, p. 98, grifo nosso).

La Trinidad Santa, hijo, como leemos, se refiere al Padre, al Hijo y al Espíritu Santo. No me atrevo ni puedo decirle lo que tendría que consignarte al respecto en este capítulo de mi pequeno libro. Lee los escritos de los Padres ortodoxos y hallarás lo que es la Trinidad. (DHUODA, 1995, p. 73, grifo nosso).

El respecto en la oración [...] No obstante, se llama reverencia en virtud de aquello que es venerable y que debes perseguir con la profunda disposición del corazón y limpia inclinación de la inteligencia. (DHUODA, 1995, p. 76, grifo nosso).

[...] Siete son los dones del Espíritu Santo, como está escrito en el profeta Isaías: Espíritu de sabiduría, espíritu de inteligencia, espíritu de consejo, espíritu de fortaleza, espíritu de ciencia, espíritu de piedad y espíritu de temor de Dios. Sin duda, hay tres clases de espíritus: el de los ángeles, el de los hombres y el de los animales y reptiles. (DHUODA, 1995, p. 113, grifo nosso).

[...] Como el juego de las tablas entre los otros juegos mundanos aparece ahora como él más conveniente y adaptado a los jóvenes [...] (DHUODA, 1995, p. 55, grifo nosso).

Na primeira passagem, a própria autora explicita sua fonte para mostrar ao filho a importância da reciprocidade das ações: se souber amar, poderá ser amado (reconhecido, querido...). Nesse mesmo excerto, ao chamar a atenção para quando se pronuncia (e se escreve) no singular e/ou no plural, ela mostra a preocupação de lhe ensinar regras gramaticais. Na segunda citação, embora não nomine o autor, ela deixa clara a indicação da leitura dos Padres da Igreja Católica sobre o mistério da Santíssima Trindade. Observamos quanto a isso que um deles, Agostinho de Hipona, tratou de forma 
intensa dessa doutrina ${ }^{6}$. No terceiro excerto de Dhuoda, aparece o título da vigésima regra de Bento de Nursia e, em seguida, uma breve explicação de seu significado. Na quarta passagem, a autora faz referência à Sagrada Escritura ${ }^{7}$ (ao apresentar os sete dons do Espírito Santo retirado no livro de Isaías - Is. 11,2) e a Gregório Magno (ao classificar os espíritos, especialmente, a primeira categoria dos anjos que é tema de um de seus escritos - Homilia sobre o Evangelho ${ }^{8}$ - Homilia 34, 7-10). Na quinta e última citação, segundo Merino (1995), Dhuoda apoia-se nas Etimologias (Cf. Livro XVIII) de Isidoro de Sevilha para explicitar sobre os jogos de tabuleiro (um entretenimento que aflorava o desenvolvimento da memória - pois era preciso conhecer as regras do jogo; a capacidade de concentração, competição e destreza dos membros da nobreza, enfim, elementos ou recursos educativos da forma de pensar própria do mundo medieval, que é a Escolástica ${ }^{9}$ ).

Os autores supracitados fundamentam a formação escolástica de Dhuoda. Em relação aos escritos sagrados, observamos que estes figuravam como fundamento educativo. A Bíblia (2002) era fonte de sabedoria para a época. Uma passagem do livro de Tiago dá uma ideia da importância desses ensinamentos: os homens daquela sociedade deveriam aprender a se mirar nos ensinamentos como espelho.

Tornai-vos praticante da Palavra e não simples ouvintes, enganando-vos a vós mesmos! Com efeito, aquele que ouve a Palavra e não a pratica, assemelha-se ao homem que, observando seu rosto no espelho, se limita a observar-se e vai-se embora, esquecendo-se logo da sua aparência. [...] (Tg. 1, 22-24).

Dhuoda $^{10}$ menciona e interpreta essa passagem do apóstolo Tiago, levando-nos a refletir no que, na atualidade, compreendemos acerca da relação entre teoria e prática e, também, na questão do

\footnotetext{
${ }^{6}$ Na obra De Trinitate, Agostinho de Hipona, teólogo e doutor da Igreja, tentou exaustivamente compreender e tratar deste mistério. Após muito trabalho, reflexão e meditação, ele chegou ao entendimento de que a mente humana era demasiado limitada para assimilar a complexidade de tal dogma. Contudo, havia uma possibilidade: a de quando chegarem à vida eterna encontrarem no Paraíso o Pai, o Filho e o Espírito Santo (SANTO AGOSTINHO, 2007).

${ }^{7}$ A fundamentação nos escritos sagrados é muito recorrente na obra de Dhuoda. A autora, praticamente, cita todos os livros que compõem a Sagrada Escritura: Gênesis, Êxodo, Levítico, Números, Deuteronômio, Josué, Juízes, I e II Samuel, I e II Reis, I e II Crônicas, Tobias, Judite, Ester, I e II Macabeus, Jó, Salmos (sendo este o livro que contem mais citações no Manual), Provérbios, Eclesiastes, Cânticos, Sabedoria, Eclesiástico, Isaías, Jeremias, Lamentações, Ezequiel, Daniel, Oseias, Joel, Jonas, Ageu, Zacarias, Malaquias, Mateus, Marcos, Lucas, João, Atos dos Apóstolos, Romanos, Coríntios, Gálatas, Efésios, Filipenses, Tessalonicenses, I e II Timóteo, Tito, Hebreus, São Tiago, I Pedro, I São João e Apocalipse. ${ }^{8}$ São Gregório Magno (2009, p. 22) assim escreve acerca da categoria dos santos anjos: "Los santos ángeles (Homilía 34, 7-10). Son nueve los coros de los ángeles. Por testimonio de la Escritura sabemos que hay ciertamente ángeles, arcángeles, virtudes, potestades, principados, dominaciones, tronos, querubines y serafines".

${ }^{9}$ A Escolástica, segundo Oliveira (2013, p. 42), “[...] foi a um só tempo a religião cristã e o conhecimento greco-romano, o seu filosofar chegava até os humildes por meio da religiosidade, ensinando e pregando a sabedoria contida nos Escritos Sagrados, ditava a forma como os pobres deviam pensar e se comportar. Ao ensinar, nos mosteiros, nas escolas e na universidade, o conhecimento antigo permeado pelos escritos sagrados, os mestres escolásticos, também expunham a forma como os futuros monges, os filhos de nobres, em síntese, os futuros dirigentes dos poderes eclesiásticos e laicos deveriam pensar e agir".

10 “[...] si alguno se contenta com oír la Palabra sin ponerla em prática, esse se parece al que contempla su imagen em um espejo: se contempla, pero, em yéndose, se olvida de como és” (SANTIAGO apud DHUODA, 1995, p. 19).
} 
compromisso. Desse modo, de que vale ouvir belas palavras, orientações, exortações se não as transformamos em ações? Dhuoda explicita a seu primogênito que não é suficiente conhecer as virtudes e os ensinamentos expostos no Manual, afirmando que ele precisa praticá-los em seu cotidiano, precisa torná-los um hábito.

Segundo Dhuoda, o apóstolo constrói uma analogia. Aquele que ouve a Palavra, mas não a pratica e não a interioriza, deixando-a exterior a si (só a ouve), é semelhante àquele que, mesmo observando seu rosto no espelho, esquece-se de seu semblante, já que apenas o contempla. Ela deixa claro, portanto, que importantes são os valores que cada um conserva e não os que aparenta conservar; o mesmo ela afirma das palavras, cuja importância está em seu significado e não somente na forma como estão escritas ou faladas.

Assim, além de hábitos, observamos, por meio dos escritos estudados, que os autores medievais tratam a linguagem de uma maneira muito distinta da nossa. Um autor que nos esclarece a este respeito é Lauand.

Se para nós a linguagem costuma ser considerada como mera convenção (e nem reparamos, por exemplo, que coleira, colar, colarinho se relacionam com colo; ou que pulseira procede de pulso); na Idade Média, pelo contrário, anseia-se por saborear a transparência de cada palavra. Daí a extrema importância que os autores medievais dão às etimologias [...] (LAUAND, 1986, p. 123).

De fato, logo no início do Manual, Dhuoda explica longamente o significado da palavra Manual.

\begin{abstract}
$<<$ Manus $>>$ [mano] puede referirse a muchas cosas; algunas veces significa el poder de Dios, otras el del Hijo; algunas veces se refiere al mismo Hijo en persona. El poder de Dios, como dice el Apóstol: Humillaos bajo la poderosa mano de Dios; el poder del Hijo, como afirmo Daniel: Su poder es un poder eterno; otras veces [se refiere] al mismo Hijo en persona, cuando dice el salmista: Envía tu poder de lo alto, es decir tu Hijo de lo más alto de los cielos. Todas estas cosas y otras parecidas hay que entenderlas como operación y poder santos, porque la $<<$ mano $>>$ significa la obra perfecta, como dice la Escritura: La mano del Señor está sobre mí, o sea la redención, porque conduce a los creyentes a la perfección; y también: La mano del Señor estaba sobre mi y me confortaba; y de nuevo: Porque su mano está com él.

$<<$ Alis $>>$, aunque tiene muchas significaciones, sin embargo en este lugar conforme a la opinión de los Padres ló referiré a três sentidos, o sea a $<<$ scopos $>>$ que significa destino, $<<$ consumatio $>>$ que indica perfección, $\mathrm{y}<<$ consecución $>>$ que es acabamiento; o también $<<$ ales $>>$ se refiere al heraldo y pregonero de la luz, que trae consigo el fin de la noche y presagia la luz del dia. ¿Qué sentido debe tener el término Manual sino el de fin de la ignorancia? Se entinde también por mensajero al que presagia el porvenir, como si dijera: $L a$ noche precedió, pero el dia se acerco, es decir Cristo, aquel que precisamente dijo: Si yo soy el día y vosotros las horas, seguidme, etc. (DHUODA, 1995, p.47-48, grifos da autora).
\end{abstract}

Para Dhuoda, a junção de MANUS+ALIS resulta em vários significados. Dentre eles, uma perspectiva bíblica para a primeira palavra (MANUS): a mão [o poder] de Deus e do filho d'Este. É 
a mão, ou o poder, do ser divino que conduz os homens para a perfeição. A segunda palavra (ALIS) pode significar fim, ou o canto da ave anunciando o fim da noite e o início do novo dia [a luz]. Assim, para ela, o sentido da palavra estaria relacionado ao fim da ignorância e ao raiar da luz divina. É com sentido e significado que Dhuoda redige seu Manual prezando pela formação de seu filho.

\section{O MANUAL DE DHUODA: UM ESPELHO DE PRÍNCIPE}

Ao considerarmos o movimento histórico e a contribuição de Dhuoda para a educação daquele período, observamos que alguns autores, como Riché (1975), Pernoud (1984), Wemple (1990), Nunes (1995), Merino (1995), apresentam importantes elementos acerca do Manual desta mulher e nos informam a respeito da influência do pensamento dessa autora no comportamento de homens daquele momento.

Com relação à influência do Manual de Dhuoda, salienta-se que ele é considerado o mais antigo tratado francês de Educação (RICHÉ, 1975; PERNOUD, 1984; NUNES, 1995). No período, ele teria sido o único no gênero e se distinguiria dos demais Espelhos carolíngios, por ter sido redigido por uma mulher e mãe; e não por um clérigo, como de costume. Esses escritos eram muito comuns naquela época, visando especialmente à formação moral dos governantes.

\footnotetext{
O abade Smaragdo, provavelmente irlandês, do mosteiro Saint-Mihiel-s-Meuse conta para Carlos Magno as virtudes dos reis do Antigo Testamento na sua obra Via Regia. Jonas, bispo de Orleães de 818 a 843, dedicou ao rei Pepino da Aquitânia, em 834, o seu Espelho de Paz, De institutione regia, em que enaltece o sentido cristão da realeza e enumera os direitos e os deveres dos reis. Noutra obra, a De institutione laicali ou Espelho Leigo, dedicada ao conde Matfredo de Orleães sobre os deveres morais das pessoas casadas, Jonas ensina aos senhores que não devem ambicionar os bens da Igreja particular localizada nos seus domínios.

O irlandês Sedulius Scottus, de Liège, dedicou provavelmente ao rei da Lotaríngia, Lotário II, o seu Espelho dos Príncipes, De rectoribus christianis, composto entre 855 e 859 . Sedúlio esboça as figuras do bote e do mau rei e ensina que o governo de um rei justo se assenta nos oito pilares da verdade, da perseverança, liberalidade, palavra afável, amizade com os bons, a diminuição dos impostos, a eqüidade nos juízos entre os ricos e os pobres, e o castigo dos maus (NUNES, 1979, p. 163).
}

Assim, sem perder seu vínculo religioso, essas obras serviam como parâmetro para a ação dos governantes, constituíam instrumentos para o desempenho de suas funções. Cumpre observar que, embora identifique nos referidos espelhos importantes princípios a ser seguidos, Nunes afirma que a obra de Dhuoda não só se insere no gênero Espelho de príncipe como também considera sua erudição revelando, assim, um Manual notável, em termos de erudição, em relação a outros escritos similares.

Não resta a menor dúvida, todavia, de que o mais perfeito Espelho da primeira idade Média foi o Manual de Dhuoda, e isso demonstra que as mulheres podiam igualar-se aos homens e aos clérigos mais instruídos e, por vezes, até mesmo superá-los. A nobre senhora Dhuoda 
começou a escrever um manual de alto valor educativo para o seu filho Guilherme, a 30 de novembro de 841, e terminou-o a 2 de fevereiro de 843 (NUNES, 1979, p. 164).

Podemos inferir que esse destaque se deve ao caráter pedagógico de suas orientações, especialmente ao duplo ensinamento contido em seus conselhos: de um lado, o teor religioso e, de outro, o aristocrático. Em outras palavras, deve-se ao fato de que as normas de educação, de comportamento e de convivência social entre todos os homens teriam como finalidade a formação de um 'perfeito' nobre. Normas essas delineadas como particularidades desse estilo literário, que podem ser observadas em Dhuoda.

Esse modelo de educação converge para a ideia aristotélica de hábito, por ser este um fundamento que pressupõe aliar os conhecimentos teóricos aos práticos. Saber, por exemplo, orar, respeitar o outro, cumprir com suas obrigações imperiais, enfim, ser fiel implicaria, necessariamente, na prática desses ensinamentos. É, nesse sentido, que Guilherme teria condições de conciliar os preceitos religiosos com os aristocráticos.

Segundo La Rosa, no Manual de Dhuoda são apresentadas regras elementares para a formação aristocrática e outras noções inerentes ao ato de ensinar. A finalidade é ensinar o primogênito a ser um cavalheiro, o que significa ser um homem de conduta irrepreensível, portanto, virtuoso, dotado de educação, cultura e de delicadeza de trato. Isto seria possível por meio da prática das virtudes na terra, ato que, ao mesmo tempo, o levaria a alcançar a salvação eterna. No entendimento do autor, ao transmitir esses conhecimentos, Dhuoda apresenta um ideal de vida cristã para os laicos; afinal, Guilherme é um deles.

[...]Ella enseña a su hijo la imagen del perfecto gentilhombre cristiano, rico por las virtudes y el atractivo de su estado aristocrático, que busca la salvación eterna permaneciendo en el mundo, adornado por las cuatro virtudes cardinales y sostenido por las virtudes instrumentales de la discreción, la alegria y la generosidad (LA ROSA apud MERINO, 1995, p. 29).

A excelência nas ações delineia a concepção de virtude, do modelo ideal de vida naquela sociedade. Relacionado ao movimento histórico do século IX, marcado por tantos conflitos, o ideal de vida preconizado no Manual de Dhuoda expressaria, em essência [a exemplo das virtudes cardeais], a fé e a esperança em tempos melhores, bem como a ação e posicionamento dessa figura feminina no meio em que vivia.

Wemple (1990), por sua vez, mostra-nos que essa inferência tem validade. Afirma a autora que, na Alta Idade Média, algumas mulheres acompanharam e contribuíram com seu conhecimento, dentro de suas possibilidades, para o movimento social de seu tempo. 
Na Alta Idade Média, ao lado dos clérigos e dos monges havia certas mulheres com uma educação assinalável. Eram todas nobres ou religiosas. Entre as primeiras mulheres germânicas está Amalasunta, filha de Teodorico o Grande, o rei ostrogodo da Itália. [...] Como o seu pai, ela tinha um profundo respeito pela cultura, pela literatura e pelo direito romanos. Conservamos dela três cartas, escritas a Teodora, a Justiniano e ao Senado de Roma. Outra mulher de algum renome foi Euquéria, que era casada com o governador de Marselha e cujo epigrama foi conservado por Fortunato. O seu curto poema sobre um pretendente de baixa extracção é rico de metáforas subtis e complexas. A terceira mulher culta cujo trabalho conhecemos é Duoda, mulher de Bernardo de Septimânia, que instruiu o filho mais velho, Guilherme, nos deveres espirituais, morais e feudais do seu tempo (WEMPLE, 1990, p. 261).

Desse modo, algumas mulheres, ao serem também partícipes, souberam, nas condições que lhes eram postas, influenciar e contribuir para a educação do período em que viviam. Nessa linha, Dhuoda contribuiu com uma educação pautada nos deveres espirituais, morais e feudais de sua época.

Atenta à formação do filho, tendo em vista as condições sociais daquele momento histórico, a autora insiste para que ele leia o Manual para salvação de sua alma [intelecto] e de seu corpo. Este objetivo poderia ser atingido por meio da sabedoria, obtida pela apropriação dos ensinamentos contidos no Manual e do laço jurídico, estabelecido por meio do juramento de fidelidade ao suserano, Carlos, o Calvo.

Tienes a Carlos como señor, porque Dios, como creo, y tu padre Bernardo lo han elegido, para que tu le sirvas ya desde los primeiros años de tu juventud com todas tus fuerzas; ten en cuenta que has salido de una família elevada y noble por ambos padres; no le sirvas sólo por ser agradable a tus ojos, sino también conforme a tu inteligência, tanto mediante el cuerpo como mediante el alma; guárdale em todo acontecimiento una fidelidad provechosa, leal y segura (DHUODA, 1995, p. 86).

Na advertência sobre a conduta a ser adotada diante do seu rei e senhor, Dhuoda afirma que é em suas atitudes que o filho manifestará sua nobre linhagem, pois, a seu ver, são as atitudes que revelam a origem da pessoa. Explica que servir a Carlos, o Calvo, foi uma 'escolha' do pai, Bernardo, guiado por Deus. Por isso, Guilherme deve desempenhar seu serviço não apenas lhe sendo agradável, mas com toda a dedicação corporal e espiritual. Afinal, cumpre salientar que se tratava de um momento de guerra entre os filhos de Luís, o Piedoso, e, portanto, ser fiel ao seu senhor (no caso de Guilherme, ser fiel a Carlos, o Calvo), significava manter-se vivo. Com essa atitude, ele experimentaria a fidelidade sincera e segura.

Efectivamente, en la lectura santa encontrarás lo que hay que rezar y lo que se há de evitar, lo que hay que prevenir, lo que hay que buscar, o lo que debes cuidar en todas las cosas. [...] Sobre la asiduidad de la oración nos advirte el Apóstol cuando dice: Orad sin interrupción. [...] Todo lo que hagas de bueno en esta vida, eso precisamente intercederá incesantemente por ti ante el Señor. [...] Por ello te exhorto a que tu espíritu se mantenga vigilante y presto, y siempre puro y limpio, en una lectura y uma oración la más digna posible (DHUODA, 1995, p. 155, grifo da autora). 
Por considerar que os hábitos e as ações na terra são o que conduzem ou não ao caminho celeste, Dhuoda reitera a importância de ser fiel a Deus, explicando que a maneira propícia para atingir tal intento é a das orações. Por isso, procura convencer Guilherme a orar a qualquer hora e em todo momento: ele deveria recitar orações por si, por sua família, por seu senhor e pelos familiares deste. Reitera que somente a fidelidade nas ações, juntamente com a constante oração poderia ajudálo a passar pelas adversidades que poderia encontrar em tempos conturbados como aquele.

Considerando que a fidelidade se apresentava como preceito educativo a ser aprendido por Guilherme, entendemos que essa virtude era necessária naquele momento. Tornando-a um hábito em suas ações cotidianas, esse jovem, potencialmente, cumpriria com seu dever na corte e, ao mesmo tempo, estaria se apropriando do processo de formação almejado por sua 'educadora'. Dhuoda o instrui para que ele possa agir conscientemente, o que significa que seu desejo é formar um exímio homem para aquela realidade.

\section{CONSIDERAÇÕES FINAIS}

Essa análise nos possibilitou apresentar um estudo sobre o papel desempenhado pela mulher no processo educativo medieval do século IX. La educación Cristiana de mi hijo, a única obra que os estudiosos de Dhuoda reconhecem como de sua autoria, oferece-nos alguns aprendizados: o conhecimento histórico, pois elucida o conturbado contexto do qual a autora foi partícipe; o educativo, por se inserir nos padrões formativos do gênero literário Espelho de Príncipe e, com eles, a ação e atuação de uma mulher no processo educativo do reino carolíngio. Ao prezar pela formação humana e intelectual de seu filho (Guilherme), Dhuoda redigiu o Manual fundamentando-se na formação escolástica que recebera em sua época.

Foi possível verificar que o preceito da fidelidade era fundamental para a sociedade feudal do século IX, sendo essa a razão para ser ensinado como virtude e como um hábito a ser adquirido por Guilherme. Dhuoda demonstra compreender o contexto do qual foi partícipe e, por dar pistas disso, ela nos leva a pensar nos embates de nosso tempo e em como educamos de acordo com eles. Com Dhuoda, aprendemos que os acontecimentos políticos, econômicos, sociais e históricos devem ser levados em consideração, pois é o conhecimento deles que nos permite ter consciência do mundo à nossa volta e alcançar a educação pretendida.

Nesse sentido, consideramos a educação uma ação a ser desenvolvida pela e para as pessoas, de modo que, em conjunto, as gerações adultas e jovens/crianças compreendam e exerçam esse processo de ensinar e aprender. Compete aos adultos orientar os jovens/crianças sobre o que é 
importante, quais são as necessidades, ideais, cultura, costumes e outros aspectos que caracterizam determinada sociedade.

Diante disso, apesar de vários séculos nos distanciarem dessa autora, um aspecto é fundamental: independentemente do período tratado, a preocupação com a formação, ou seja, com o que e para quê educamos revela-se atual. Por isso, para discorrermos sobre o Manual de Dhuoda como projeto de educação, evidenciando o papel da mulher no processo educativo da Idade Média foi importante compreender algumas das questões que perpassaram esse período. Como afirma Bloch (2001), existe 'um fundo permanente' que permeia os momentos históricos e se mostram presentes para o desenvolvimento social.

Desse modo, o Manual de Dhuoda pode ser considerado e analisado como atuação e decisão de uma mulher, no decorrer do processo histórico e, também, como um projeto de educação. Como preconiza o Artigo $1^{\circ}$ da Lei de Diretrizes e Bases da Educação Nacional (LDBEN) n. 9394, de 20 de dezembro de 1996, “[...] a educação compreende e abrange os processos formativos desenvolvidos no seio da família" (BRASIL, 1996). É dessa perspectiva que, para nós, há uma aproximação com o Manual de Dhuoda, no qual estão expressos justamente tanto a atuação de uma educadora que com seu escrito expressa os processos formativos, a proposta pedagógica, quanto os preceitos adotados pela família de Guilherme e canalizados para a sua formação. De posse desse escrito, ele teria condições de se apropriar do processo e conduzir sua formação humana e intelectiva.

Assim, é preciso considerar que no projeto de educar o filho, Dhuoda nos permite compreender elementos essenciais do seu tempo e a fidelidade ao rei e aos demais homens era um desses elementos, portanto, o seu filho precisaria aprender e praticar essa virtude.

\section{REFERÊNCIAS}

ARISTÓTELES. Ética a Nicômaco. Trad. de Mário da Gama Kury. Brasília: Editora Universidade de Brasília, 1985.

BÍBLIA. Português. Bíblia de Jerusalém. Trad. de Euclides Martins Balancin et al. São Paulo: Paulus, 2002.

BLOCH, Marc. Apologia da História ou o ofício de historiador. Rio de Janeiro: Zahar, 2001.

BRASIL. Lei de Diretrizes e Bases da Educação Nacional. Lei no 9394, de 20 de dezembro de 1996. Estabelece as diretrizes e bases da educação nacional. Brasília, DF, 1996.

BRAUDEL, Fernand. Escritos sobre a história. 2. ed. São Paulo: Perspectiva, 2011. 
DIAS, Ivone Aparecida. A educação feminina na Idade Média: damas e religiosas. 145 f.

Dissertação (Mestrado em Educação) - Universidade Estadual de Maringá. Maringá, 2001.

DIB, Marlene Aparecida Marchi. A educação cristã de meu filho: uma reflexão sobre a crise carolíngia do século IX. 144 f. Dissertação (Mestrado em Educação), Universidade Estadual de Maringá, 2005.

DHUODA. La Educación cristiana de mi hijo. Pamplona: Editora Eunate, 1995.

ECO, Umberto (Org.). Idade Média - Bárbaros, cristãos e muçulmanos. Portugal: Dom Quixote, 2010. Disponível em:

$<$ http://books.google.com.br/books?id=YA9ZLbUyjLsC\&printsec $=$ frontcover\&dq $=$ idade $+\mathrm{m} \% \mathrm{C} 3 \%$ A9dia + umberto + eco\&hl=pt-BR\&sa $=$ X\&ei $=-$

CbLUpCFHMHesASOIYKwDQ\&ved=0CDcQ6AEwAQ\#v=onepage\&q=idade $\% 20 \mathrm{~m} \% \mathrm{C3} \% \mathrm{~A} 9 \mathrm{dia}$ $\% 20$ umberto $\% 20$ eco\&f $=$ false $>$. Acesso em: 06/12/2017.

ESCANDÓN, Carmen. La historia de Mexico desde el gênero. Ensayos, Universidad Autonoma Metropolitana-Iztapalapa, v. 5, 1991.

FALBEL, Nachman. Hincmar, arcebispo de Reims, e os dois poderes. In: SOUZA, José Antônio de C. R. (Org.). O reino e o sacerdócio: o pensamento político na Alta Idade Média. Porto Alegre: EDIPUCRS, 1995.

FEBVRE, Lucien. Combates pela história. Lisboa: Editorial Presença, 1989.

GUIZOT, François. Historia da civilisação na Europa. Lisboa: Parceria Antonio Maria Pereira Livraria Editora e officinas Typographica e de encadernação, 1907.

KELLY, Joan. The Social relations of sexes - Methodological Implications of Women's History. Signs, 1, 1976, p. 809-826.

LAUAND, Jean Luiz (org.). Educação, teatro e matemática medievais. São Paulo: Perspectiva, 1986.

MERINO, Marcelo. "Introdução". In: DHUODA. La Educación cristiana de mi hijo. Pamplona: Editora Eunate, 1995.

MONTESQUIEU, Charles Louis de Secondant. O espírito das leis. Trad. Fernando Henrique Cardoso e Leoncio Martins Rodrigues. Brasília: Editora Universidade de Brasília, 1982. 
NUNES, Ruy. História da educação na Idade Média. São Paulo: EPU/Editora da Universidade de São Paulo, 1979.

NUNES, Ruy. O dever da fidelidade no manual de Dhuoda. In: SOUZA, José Antonio de C. R. (org.). O reino e o sacerdócio: o pensamento político na Alta Idade Média. Porto Alegre: EDIPUCRS, 1995.

OLIVEIRA, Terezinha. A Escolástica como Filosofia e Método de Ensino na Universidade Medieval: uma reflexão sobre o Mestre Tomás de Aquino. Revista Notandum, São Paulo/Porto, n. 32, p. 37-50, maio-ago 2013.

. Guizot e a Idade Média: civilização e lutas políticas. Tese (Doutorado em História) Faculdade de Ciências e Letras, Universidade Estadual Paulista Julio de Mesquita Filho. Assis, 1997.

OLIVEIRA, Terezinha; MENDES, Claudinei Magno Magre (Org. e trad.). O estado da sociedade religiosa no século V (François Guizot). Apontamentos, Maringá, n. 77, 1999.

PASTOR, Reyna. Para una historia social de la mujer hispano-medieval - Problemática y puntos de vista. In: FONQUERNE, Yves-René. La condición de la mujer em la Edad Media. Madrid, Casa de Veázquez - Universidad Complutense de Madrid, 1986, p. 187- 214. Disponível em:

$<$ https://books.google.com.br/books?id=BV35vD0AxhoC\&pg=PA187\&lpg=PA187\&dq=Reyna $+\mathrm{P}$ astor+para+una+historia+social+de+la+mujer+hispanomedieval\&source $=$ bl\&ots $=1 \mathrm{~Gb} 7 Z \mathrm{jKVLT} \&$ sig $=$ oFISR51UUoec35Qo6pot0zU_j6s\&hl=ptBR\&sa $=$ X\&ved $=0$ ahUKEwiG-

LTK_a3UAhWBH5AKHV59C7kQ6AEIMDAC\#v=onepage\&q=Reyna\%20Pastor\%20para\%20una $\% 20$ historia $\% 20$ social\%20de\%20la\%20mujer\%20hispano-medieval\&f=false $>$. Acesso em: $19 / 12 / 2017$.

PERNOUD, Régine. A mulher no tempo das catedrais. Lisboa: Gradiva, 1984.

PERROT, Michelle. Escrever uma história das mulheres: relato de uma experiência. Cadernos Pagu: Campinas, v. 4, p. 9-28, 1995. Disponível em: <

file://D:/Downloads/cadpagu_1995_4_2_PERROT.pdf>. Acesso em: 14/07/2017.

PINTO, Céli Regina Jardim. Feminismo, história e poder. Revista de Sociologia e Política:

Curitiba, v. 18, n. 36, online, jun. 2010. Disponível em:<

http://www.scielo.br/scielo.php?script=sci_arttext\&pid=S0104-

$44782010000200003 \& \operatorname{lng}=$ pt\&nrm=iso $>$. Acesso em: 12/09/2017.

RICHÉ, Pierre. Introdução. In: DHUODA. Manuel pour mon fils. Paris: Soucers Chrétiennes, 1975. 
ROIZ, Diogo da Silva. A discreta e sedutora "História das mulheres". Cadernos Pagu: Campinas, n. 30, online, 2008. Disponível em: $<$

http://www.scielo.br/scielo.php?script=sci_arttext\&pid=S0104-83332008000100025\#nt $>$. Acesso em: 11/09/2017.

SANTO AGOSTINHO. De Trinitate/Trindade. Paulinas Editora: Prior Velho, 2007. Disponível em: <http://www.lusosofia.net/textos/agostinho_de_hipona_de_trinitate_livros_ix_xiii.pdf $>$. Acesso 08/01/2017.

SÃO GREGÓRIO MAGNO. Antologia (Homilias sobre o Evangelho; Regra Pastoral; Tratado sobre o Livro de Jó), 2009. Disponível em:

$<$ http://mercaba.files.wordpress.com/2009/03/gregoriomagnoantologia.pdf $>$. Acesso em: $11 / 09 / 2017$.

SCOTT, Joan. Gender: a useful category of historical analyses. Gender and the politics of history. New York, Columbia University Press. 1989.

ZILLES, Urbano. Fé e razão no pensamento medieval. Porto Alegre: Edipucrs, 1996.

WEMPLE, Suzane Fonay. As mulheres do século V ao século X. In: DUBY, Georges; PERROT, Michelle (orgs.). História das mulheres no Ocidente. Lisboa: Afrontamento, 1990.

Agência de Fomento CAPES - Demanda social, em nível de doutorado (ano vigente 2015-2019) 